\title{
Retrospective Analysis of the Association of Non-Carious Cervical Lesions with Bruxism
}

\author{
Angelica Jane Bustos', Tanya Al-Talib², Neamat Hassan Abubakr ${ }^{3 *}$ \\ ${ }^{1}$ School of Dental Medicine, University of Nevada, Las Vegas, Nevada, USA \\ ${ }^{2}$ Department of Clinical Sciences, University of Nevada, Las Vegas, Nevada, USA \\ ${ }^{3}$ Department of Biomedical Sciences, University of Nevada, Las Vegas, Nevada, USA \\ Email: *neamat.hassan@unlv.edu
}

How to cite this paper: Bustos, A.J., Al-Talib, T. and Abubakr, N.H. (2020) Retrospective Analysis of the Association of Non-Carious Cervical Lesions with Bruxism. Open Journal of Stomatology, 10, 11-18.

https://doi.org/10.4236/ojst.2020.102002

Received: December 13, 2019

Accepted: January 11, 2020

Published: January 14, 2020

Copyright $\odot 2020$ by author(s) and Scientific Research Publishing Inc. This work is licensed under the Creative Commons Attribution International License (CC BY 4.0).

http://creativecommons.org/licenses/by/4.0/

\begin{abstract}
Recently, bruxism became the center of attention for the etiological research of non-carious cervical lesions (NCCLs). The present study aims to investigate the presence and types of NCCLs associated with bruxism. Retrospective keywords search of the clinical notes of all patient charts in axiUm ${ }^{\text {Tw }}$ was performed using the terms "bruxism", "attrition", "abrasion", "erosion", and "abfraction". All bruxer patients 18 years and older who presented to the UNLV School of Dental Medicine (01/01/2014 to 09/30/2018) with the complete record were included. To determine the statistical analysis implications, the chi-square test was used. Commonest types of NCCL associated with bruxism were attrition and abfraction. Five hundred seventeen cases had multifactorial lesions. Anterior maxillary teeth followed by mandibular anterior were the most affected teeth. Abfraction lesions were mainly sighted in maxillary premolars, followed by maxillary canines. Within the limitation of the present investigation, it was concluded that attrition and abfraction were highly associated with bruxism.
\end{abstract}

\section{Keywords}

Bruxism, Non-Carious Cervical Lesions (NCCLs), Attrition, Abfraction

\section{Introduction}

Several kinds of oral parafunctional habits can affect the oral system; this includes bruxism. The prevalence of bruxism varies greatly from $5 \%$ to greater than $90 \%$ [1]. The public awareness of bruxism is low and usually, bruxism is generally under-reported [2]. Bruxism can cause periodontal tissue destruction. However, the relationship between bruxism and tooth loss is not clear. Increased 
masticatory muscle activity has been thought to cause occlusal overloads, thus causing clinical complications for teeth [3]. Masticatory muscles can produce a wide range of biting forces (up to $400-1100 \mathrm{~N}$ ) [4].

Bruxism is the act of grinding or clenching one's teeth during non-functional movements and can lead to heavy occlusal stresses resulting in loss of tooth structure [5]. It has been thought to be a significant factor in the development of non-carious cervical lesions. Research has shown that a higher number of non-carious cervical lesions can be found in patients that exhibit bruxism habits. These habits include lateral excursion, centric relation prematurity, or a combination of both [6]. Non-carious cervical lesion (NCCLs) is defined as the loss of tooth tissue in the cervical region with a nonbacterial etiology [7]. NCCLs are not related to dental caries as it is the loss of tooth structure at the cementoenamel junction. As the population ages, tooth wear is becoming of great importance in the dental profession as the number and size of the lesions increase with age [8]. These lesions are a direct result of the duration, location, frequency, and magnitude of occlusal contact. If not corrected or restored improperly, these lesions could be susceptible to caries infection/lesions. The causative agents of non-carious cervical lesions are erosion, abrasion, abfraction, and attrition.

Several hypotheses about the etiology of NCCLs have been published, including acid erosion, tooth brushing, and traumatic occlusion [8]. Several Crosssectional studies showed that horizontal brushing technique [9], high frequency of tooth brushing [9] [10], and high pressure of tooth brushing [11], increase the risk of the NCCLs. In a multivariate analysis, a recently conducted retrospective case-control study showed that protrusive interferences, bruxism, age, and the presence of attrition were risk factors for the development of NCCLs [12]. The purpose of the present study was to investigate the appearance and the type of NCCLs associated with bruxism.

\section{Methods}

The Biomedical Institutional Review Board of the University of Nevada, Las Vegas, exempted this study (IRB no. 1246056-1). A retrospective keyword search of the clinical notes of all patient charts in axiUm ${ }^{\text {tw }}$ was performed using the search terms "bruxism", "attrition", "abrasion", "erosion", and "abfraction" to identify the number of cases that were documented with bruxism and non-carious cervical lesions. The selection procedure included patients who are 18 years and older who presented to the UNLV School of Dental Medicine from January 2014 to September 2018. Also, patients who presented with one or more of the search terms (bruxism, attrition, abrasion, erosion, and abfraction) were included, which resulted in a total of 5080 patient cases. Exclusion criteria included patients with: incomplete charts, no radiographic images or clinical photos, locked or deactivated charts, UNLV demographic only, and non-bruxer stating patients. After applying all exclusion criteria, the final sample size was 597 patients (Figure 1). To determine the statistical analysis implications, the chi-square test was used using graph pad Quik Calcs. 


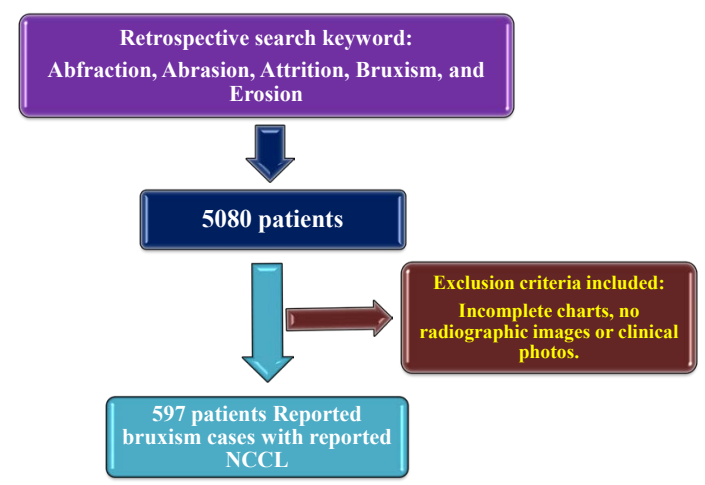

Figure 1. Descriptive data collection flowchart.

\section{Results}

Results showed that $59.6 \%$ of patients were females; 54 - 62 years were the highest age range (Table 1). The reported single type of NCCL was $34.7 \%$; while 65.3\% presented with multifactorial NCCL lesions (Figure 2). Attrition and abfraction were the most common type of non-carious cervical lesions associated with bruxism $(\mathrm{P}<0.001)$ (Figure 2). Five hundred and seventeen cases had presented with attrition which was the most significant reported lesion $(\mathrm{P}<0.001)$ (Figure 2).

The most commonly affected teeth for attrition were the mandibular anterior (48\%) followed by maxillary anterior teeth (38\%) (Figure 3).

Two hundred and seventy-nine cases presented with abfraction as the NCCLs which was statistically significant when compared with other NCCLs $(\mathrm{P}<0.001)$ (Figure 2). Abfraction lesions were mainly observed in mandibular premolars (30\%) followed by maxillary premolars (24\%) (Figure 4 ).

\section{Discussion}

Limited cross-sectional studies report the level of the association between the risk factors and the presence of NCCLs by the logistic regression odds ratio, some of the mentioned risk factors were bruxism, age and tooth brushing-related factors [11] [13] [14].

A correlation between self-reported bruxism and NCCLs was reported in some research [15] [16]. Several studies indicated that bruxers have a higher incidence of non-carious cervical lesions than non-bruxers [17] [18]. The present investigation further supports that a significant contributing factor to the formation of non-carious cervical lesions is bruxism.

The present results indicated that $65 \%$ of the sample cases had multifactorial NCCLs, which comes into agreement with previous research, which stated that it is usually recognized that NCCLs have a multifactorial etiology [11] [12] [19]. Tooth flexure is thought to be caused by abnormal occlusal loading forces, which will result in tensile and compressive forces in the cervical region of the tooth [18]. Micro-fractures in the crystalline structure of the enamel and dentin as a result of the tooth flexure makes the tooth susceptible to NCCLs [20]. 
Table 1. Sociodemographic characteristics of analyzed participants.

\begin{tabular}{ccc}
\hline & Variables & Percentage \\
\hline Male & $241(40.4 \%)$ \\
Fender & $\mathbf{1 8 - 2 6}$ & $356(59.6 \%)$ \\
& $\mathbf{2 7}-\mathbf{3 5}$ & $10(1.6 \%)$ \\
& $\mathbf{3 6}-\mathbf{4 4}$ & $54(9.1 \%)$ \\
Age groups & $\mathbf{4 5 - 5 3}$ & $117(19.6 \%)$ \\
& $\mathbf{5 4}-\mathbf{6 2}$ & $107(17.9 \%)$ \\
& $\mathbf{6 3 - 7 1}$ & $121(20.3 \%)$ \\
& $\mathbf{7 2 - 8 0}$ & $115(19.2 \%)$ \\
& $\mathbf{8 1 +}$ & $60(10.1 \%)$ \\
\hline
\end{tabular}

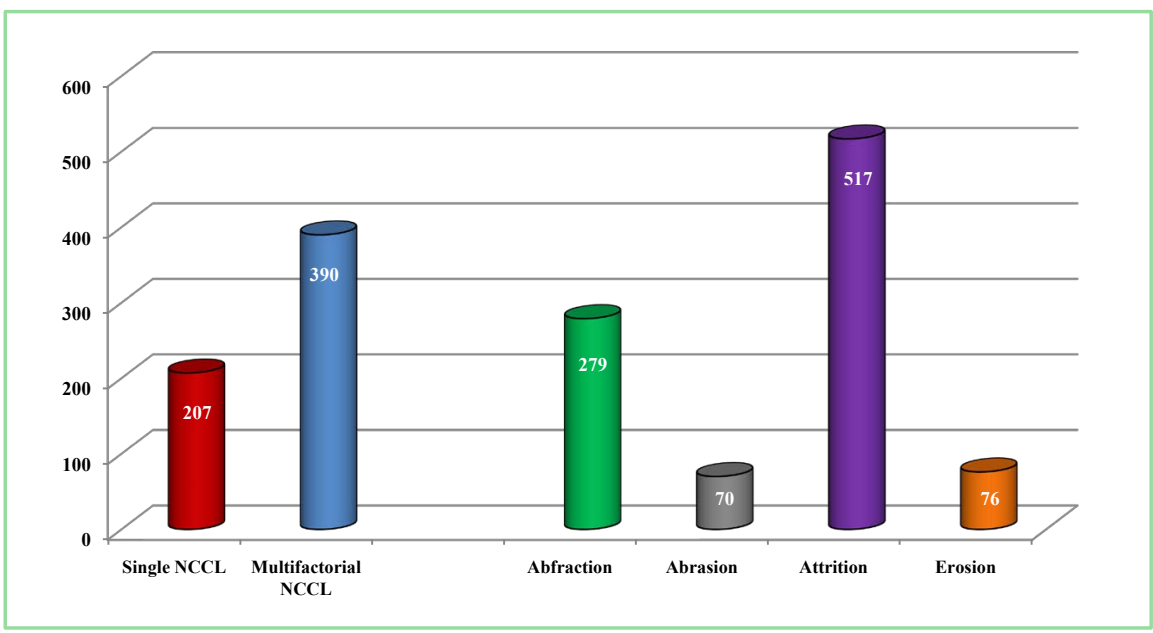

Figure 2. Distribution of the patients according to the type of NCCLs.

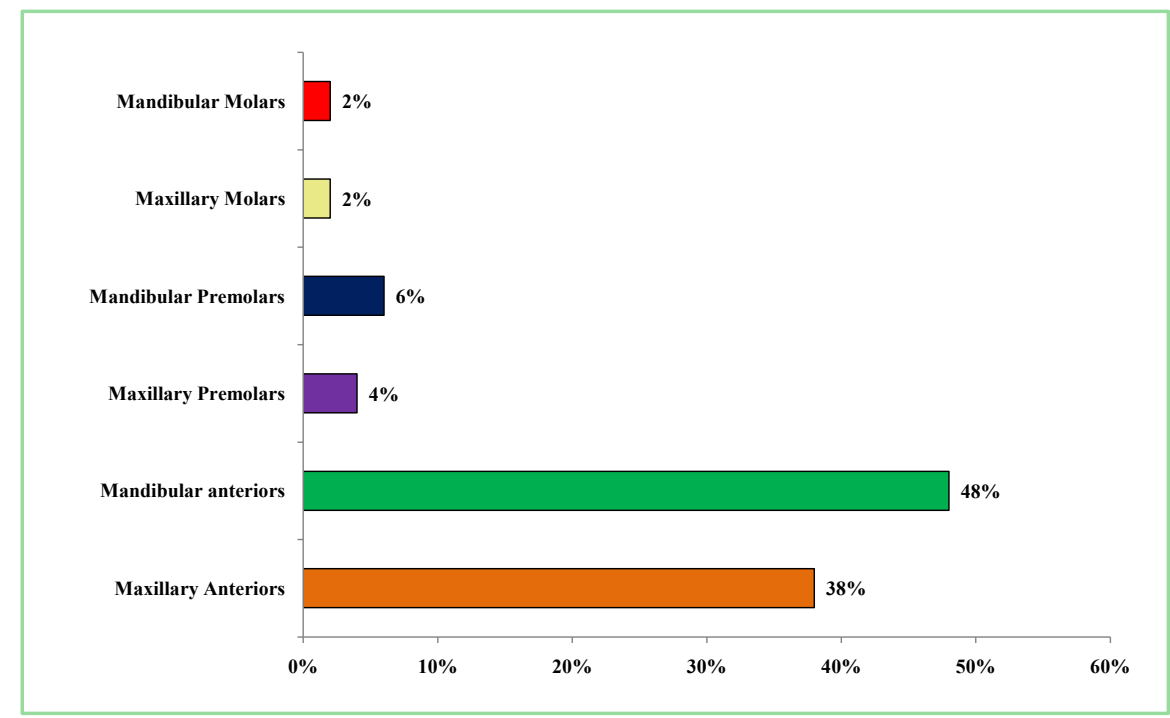

Figure 3. Distribution of attrition according to the type of tooth. 


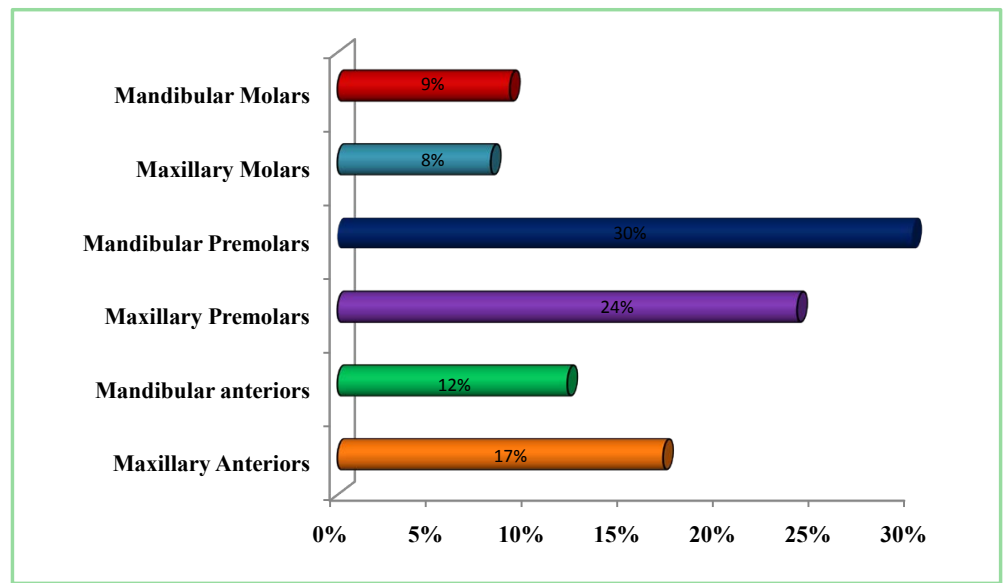

Figure 4. Distribution of abfraction according to the type of tooth.

Bruxism is a parafunctional activity that will be the reason for the development of non-physiological attrition and abfraction [21]. Results of the present investigation revealed that attrition was the most significant type of NCCLs followed by abfraction. Attrition is defined as the loss of tooth substance caused by tooth-to-tooth contact, so although it is mainly seen on the occlusal or incisal surfaces, attrition can also occur interproximal as the lateral movement of teeth produces broader interproximal contacts over time [22]. In most cases, bruxers often tend to brux in an anterior/ posterior direction or a lateral direction. If they tend to brux anterior/posteriorly marked matching wear facets are often seen on the anterior teeth [23]. Jonsgar et al. found that self-reported and partner-reported sleep bruxism was more common among individuals with attritional teeth wear [24]. Several studies related bruxism as the primary source of tooth wear and are associated with an excessive occlusal force that will lead to the development of abfraction [25] [26].

In 2013, Antonelli et al. showed that during the parafunction, the occlusal load could reach $102 \mathrm{~kg}$, and the total dental contact time for a bruxer ranges from $30 \mathrm{~min}$ to $3 \mathrm{~h}$ per day. Excessive occlusal loads promote tensions in the cervical region of the tooth, causing non-carious cervical lesions [27].

By having the ability and knowledge to identify bruxism habits, dental care providers can help prevent the development of non-carious cervical lesions by patient education and early intervention, such as the use of an occlusal guard.

\section{Conclusion}

Within the limitation of the present investigation, it was concluded that attrition and abfraction were highly associated with bruxism.

\section{Authors' Contributions}

$\mathrm{AB}$ carried out the data collection, and drafting of the manuscript.

TA performed the analysis and interpretation of data and participated in the drafting and preparing of the manuscript. 
NHA participated in the conception, design and analysis of the study, and participated in the preparation and revision of the manuscript.

All authors read and approved the final manuscript.

\section{Disclosure}

None of the authors reported any disclosures.

\section{Conflicts of Interest}

The authors declare no conflicts of interest regarding the publication of this paper.

\section{References}

[1] Lavigne, G.L., Khouy, S., Abe, S., Yamaguchi, T. and Raphael, K. (2008) Bruxism Physiology and Pathology: An Overview for Clinicians. Journal of Oral Rehabilitation, 35, 476-494. https://doi.org/10.1111/j.1365-2842.2008.01881.x

[2] Kawakami, S., Kumazaki, Y., Manda, Y., Oki, K. and Minagi, S. (2014) Specific Diurnal EMG Activity Pattern Observed in Occlusal Collapse Patients: Relationship between Diurnal Bruxism and Tooth Loss Progression. PLoS ONE, 9, e101882. https://doi.org/10.1371/journal.pone.0101882

[3] Bernhardt, O., Gesch, D., Look, J.O., Hodges, J.S., Schwahn, C., et al. (2006) The Influence of Dynamic Occlusal Interferences on Probing Depth and Attachment Level: Results of the Study of Health in Pomerania (SHIP). Journal of Periodontology, 77, 506-516. https://doi.org/10.1902/jop.2006.050167

[4] Van der Bilt, A. (2011) Assessment of Mastication with Implications for Oral Rehabilitation: A Review. Journal of Oral Rehabilitation, 38, 754-780. https://doi.org/10.1111/j.1365-2842.2010.02197.x

[5] Piotrowski, B.T., Gillette, W.B. and Hancock, E.B. (2001) Examining the Prevalence and Characteristics of Abfraction like Cervical Lesions in a Population of U.S. Veterans. The Journal of the American Dental Association, 132, 1694-1701. https://doi.org/10.14219/jada.archive.2001.0122

[6] Telles, D., Pegoraro, L.F. and Pereira, J.C. (2006) Incidence of Noncarious Cervical Lesions and Their Relation to the Presence of Wear Facets. Journal of Esthetic and Restorative Dentistry, 18, 178-183. https://doi.org/10.1111/j.1708-8240.2006.00015.x

[7] Sawlani, K., Lawson, N.C., Burgess, J.O., Lemons, J.E., Kinderknecht, K.E., Givan, D.A. and Ramp, L. (2016) Factors Influencing the Progression of Noncarious Cervical Lesions: A 5-Year Prospective Clinical Evaluation. The Journal of Prosthetic Dentistry, 115, 571-577. https://doi.org/10.1016/j.prosdent.2015.10.021

[8] Wood, I., Jawad, Z., Paisley, C. and Brunton, P. (2008) Non-Carious Cervical Tooth Surface Loss: A Literature Review. Journal of Dentistry, 36, 759-766. https://doi.org/10.1016/j.jdent.2008.06.004

[9] Bergsröm, J. and Lavstedt, S. (1979) An Epidemiologic Approach to Tooth-Brushing and Dental Abrasion. Community Dentistry and Oral Epidemiology, 7, 57-64. https://doi.org/10.1111/j.1600-0528.1979.tb01186.x

[10] Bader, J.D., McClure, F., Scurria, M.S., Shugars, D.A. and Heymann, H.O. (1996) Case Control Study of Non-Carious Cervical Lesions. Community Dentistry and Oral Epidemiology, 24, 286-291. https://doi.org/10.1111/j.1600-0528.1996.tb00861.x 
[11] Takehara, J., Takano, T., Akhter, R. and Morita, M. (2008) Correlations of Noncarious Cervical Lesions and Occlusal Factors Determined by Using Pressure-Detecting Sheet. Journal of Dentistry, 36, 774-779. https://doi.org/10.1016/j.jdent.2008.05.009

[12] Alvarez-Arenal, A., Alvarez-Menendez, L., Gonzalez-Gonzalez, I., Jiménez-Castellanos, E., Garcia-Gonzalez, M. and deLlanos-Lanchares, H. (2019) The Role of Occlusal Factors in the Presence of Noncarious Cervical Lesions in Young People: A Case-Control Study. Operative Dentistry, 44, E12-E22. https://doi.org/10.2341/18-028-C

[13] Que, K., Guo, B., Jia, Z., Chen, Z., Yang, J. and Gao, P. (2013) A Cross-Sectional Study: Non-Carious Cervical Lesions, Cervical Dentine Hypersensitivity and Related Risk Factors. Journal of Oral Rehabilitation, 40, 24-32. https://doi.org/10.1111/j.1365-2842.2012.02342.x

[14] Bernhardt, O., Gesch, D., Schwahn, C., et al. (2006) Epidemiological Evaluation of the Multifactorial Aetiology of Abfractions. Journal of Oral Rehabilitation, 33, 17-25. https://doi.org/10.1111/j.1365-2842.2006.01532.x

[15] Ommerborn, M.A., Schneider, C., Giraki, M., et al. (2007) In Vivo Evaluation of Noncarious Cervical Lesions in Sleep Bruxism Subjects. Journal of Prosthetic Dentistry, 98, 150-158. https://doi.org/10.1016/S0022-3913(07)60048-1

[16] Hatzikyriakos, A. and Menexes, G. (2008) Association between Self-Reported Bruxism Activity and Occurrence of Dental Attrition, Abfraction, and Occlusal Pits on Natural Teeth. Journal of Prosthetic Dentistry, 100, 41-46. https://doi.org/10.1016/S0022-3913(08)60135-3

[17] Xonga, F.A. (1977) Bruxism and Its Effects on the Teeth. Journal of Oral Rehabilitation, 4, 65-76. https://doi.org/10.1111/j.1365-2842.1977.tb00967.x

[18] Heymann, H.O., Sturdevant, J.R., Bayne, S., Wilder, A.D., Sluder, T.B. and Brunson, W.D. (1991) Examining Tooth Flexure Effects on Cervical Restorations: A Two-Year Clinical Study. The Journal of the American Dental Association, 122, 41-47. https://doi.org/10.1016/S0002-8177(91)25015-1

[19] Bernhardt, O., Gesch, D., Schwahn, C., Mack, F., Meyer, G., John, U., et al. (2006) Epidemiological Evaluation of the Multifactorial Aetiology of Abfractions. Journal of Oral Rehabilitation, 33, 17-25. https://doi.org/10.1111/j.1365-2842.2006.01532.x

[20] Lee, W.C. and Eakle, W.S. (1984) Possible Role of Tensile Stress in the Etiology of Cervical Erosive Lesions of Teeth. Journal of Prosthetic Dentistry, 52, 374-380. https://doi.org/10.1016/0022-3913(84)90448-7

[21] De la Hoz-Aizpurua, J.-L., Díaz-Alonso, E., LaToucheArbizu, R., et al. (2011) Sleep Bruxism. Conceptual Review and Update. Medicina Oral Patologia Oral y Cirugia Bucal, 16, e231-e238. https://doi.org/10.4317/medoral.16.e231

[22] Paesani, D.A. (2010) Toothwear. In: Paesani, D.A., Ed., Bruxism-Theory and Practice, Quintessence Publishing Co. Ltd., Surrey, 123-147.

[23] Rees, J.S. and Somi, S. (2018) A Guide to the Clinical Management of Attrition. British Dental Journal, 224, 319-323. https://doi.org/10.1038/sj.bdj.2018.169

[24] Jonsgar, C., Hordvik, P.A., Berge, M.E., Johansson, A.K., Svensson, P. and Johansson, A. (2015) Sleep Bruxism in Individuals with and without Attrition-Type Tooth Wear: An Exploratory Matched Case-Control Electromyographic Study. Journal of Dentistry, 43, 1504-1510. https://doi.org/10.1016/j.jdent.2015.10.002

[25] Lyons, K. (2001) Aetiology of Abfraction Lesions. New Zealand Dental Journal, 97, 93-98.

[26] Roomed, S.A., Malik, R. and Dunne, S.M. (2012) Stress Analysis of Occlusal Force 
in Canine Teeth and Their Role in the Development of Non-Carious Cervical Lesions: Abfraction. International Journal of Dentistry, 2012, Article ID: 234845. https://doi.org/10.1155/2012/234845

[27] Antonelli, J.R., Hottel, T.L. and Garcia-Godoy, F. (2013) Abfraction Lesions-Where Do They Come from? A Review of the Literature. The Journal of the Tennessee Dental Association, 93, 14-19. 